\title{
Shade-Tree Rehabilitation in Vanilla Agroforests is Yield Neutral and May Translate into Landscape-Scale Canopy Cover Gains
}

\author{
Dominic Andreas Martin, ${ }^{1 *} \odot$ Annemarie Wurz, ${ }^{2} \odot$ Kristina Osen, ${ }^{3} \odot$ \\ Ingo Grass, ${ }^{4} \odot$ Dirk Hölscher, ${ }^{3,5}$ Thorien Rabemanantsoa, ${ }^{6}$ \\ Teja Tscharntke, ${ }^{2,5} \odot$ and Holger Kreft ${ }^{1,5} \odot$
}

\begin{abstract}
${ }^{1}$ Biodiversity, Macroecology and Biogeography, University of Goettingen, Büsgenweg 1, 37077 Göttingen, Germany; ${ }^{2}$ Agroecology, University of Goettingen, Grisebachstr. 6, 37077 Göttingen, Germany; ${ }^{3}$ Tropical Silviculture and Forest Ecology, University of Goettingen, Büsgenweg 1, 37077 Göttingen, Germany; ${ }^{4}$ Ecology of Tropical Agricultural Systems, University of Hohenheim, Garbenstr. 13, 70599 Stuttgart, Germany; ${ }^{5}$ Centre for Biodiversity and Sustainable Land Use (CBL), University of Goettingen, Büsgenweg 1, 37077 Göttingen, Germany; ${ }^{6}$ Diversity Turn Research Project, Sambava, Madagascar
\end{abstract}

\begin{abstract}
Agroforestry can contribute to an increase in tree cover in historically forested tropical landscapes with associated gains in biodiversity and ecosystem functioning, but only if established on open land instead of underneath a forest canopy. However, declines in yields with increasing shade are common across agroforestry crops, driving shade-tree removal in forest-derived agroforests and hindering tree regrowth in open-land-derived agroforests. To understand trajectories of change in tree cover in forest- and open-land-derived agroforests, and the impacts of tree cover on vanilla yields, we studied 209 vanilla agroforests along an 88-year chronosequence in Madagascar. Additionally, we used remotely sensed canopy cover data to inves-
\end{abstract}

Received 17 June 2020; accepted 1 November 2020; published online 7 December 2020

Electronic supplementary material: The online version of this article (https://doi.org/10.1007/s10021-020-00586-5) contains supplementary material, which is available to authorized users.

Author's contributions All authors conceived ideas and planned data collection and analysis. DAM, AW, and KO coordinated the data collection; TR led the field team; DAM analysed and visualized the data; DAM led the writing of the manuscript. All authors contributed to the writing and gave final approval for publication.

*Corresponding author; e-mail: dominic.martin@uni-goettingen.de tigate tree cover change in the agricultural landscape. We found yields to vary widely but independently of canopy cover and land-use history (forest- vs. open-land-derived), averaging at $154.6 \mathrm{~kg} \mathrm{ha}^{-1}$ year $^{-1}(\mathrm{SD}=186.9)$. Furthermore, we found that forest- and open-land-derived vanilla agroforests gained canopy cover over time, but that only open-land-derived agroforests gained canopy height. Canopy cover increased also at the landscape scale: areas in the agricultural landscape with medium initial canopy cover gained $6.4 \%$ canopy cover over 10 years, but canopy cover decreased in areas with high initial canopy cover. These opposing trends suggest tree cover rehabilitation across areas covered by vanilla agroforests, whereas remnant forest fragments in the agricultural landscape were transformed or degraded. Our results indicate that yield-neutral tree rehabilitation through open-land-derived agroforestry could, if coupled with effective forest protection, provide benefits for both ecosystem functions and agricultural production in a smallholder-dominated agricultural landscape. 
Key words: agroecology; agroforestry; canopy cover; ecosystem services; land-use history; Madagascar; rehabilitation; restoration; vanilla; yield.

\section{HighLights}

- Shade-trees in agroforests are commonly cut due to trade-offs between shade and yields.

- Across a chronosequence with 209 vanilla agroforests, we do not find such trade-offs.

- The lack of this trade-off offers an opportunity for yield-neutral tree rehabilitation.

\section{INTRODUCTION}

Rehabilitation of historically forested open land is widely advocated to re-establish connectivity and increase ecosystem functions in tropical rainforest landscapes (Bastin and others 2019; Chazdon 2003). To date, governments and institutions have pledged to restore 140 million hectares of land in the tropics (Brancalion and others 2019). However, realizing those pledges could jeopardize food security if tree cover restoration replaces cropland, casting doubt on their feasibility (Eitelberg and others 2016) and desirability (Holl and Brancalion 2020). In this light, agroforests may provide an opportunity to combine trees with agricultural production on the same land (De Beenhouwer and others 2016; FAO 2017). Agroforests that are established on historically forested open land hold a particularly large potential, because open-land-derived agroforests rehabilitate selected ecosystem functions like erosion control or carbon storage on open land (Martin and others 2020b). To describe this process, we specifically use the word tree rehabilitation' based on Chazdon and others (2016), as the focus lies on the rehabilitation of ecosystem functions, without necessarily restoring ecological integrity. In contrast to this, agroforests planted under the canopy of existing forests typically contribute to forest degradation (Martin and others 2020a, b), thus hampering ecosystem functioning and ecological integrity (Coe and others 2013; McDowell and others 2020).

Nonetheless, trade-offs between shade cover and yields are common across many key agroforestry crops (Tscharntke and others 2011), limiting the potential of these agroforestry systems to contribute to tree rehabilitation in tropical rainforest landscapes. Such shade-yield trade-offs are exem- plified in coffee and cacao agroforests (Blaser and others 2018; Steffan-Dewenter and others 2007), where felling trees is typically beneficial to farmers aiming at optimizing yields. Finding a balance between ecosystem services, biodiversity and profitability thus requires targeted incentives (Tscharntke and others 2014). In their absence, a decrease in canopy cover and tree height over time commonly occurs (Tscharntke and others 2011), but time series or chronosequences, which are necessary to identify trends, are rare (see Nijmeijer and others (2019) for an exception). Finding farming techniques or crops where such trade-offs do not inherently occur would, on the other hand, offer an opportunity to profitably farm crops in high-shade agroforestry systems without the need for further incentives.

One candidate crop where shade-yield trade-offs are currently unknown is the spice vanilla. When farmed in agroforestry systems, the vanilla orchid (Vanilla planifolia) is typically grown on support trees which act as a climbing structure for the nonwoody vine (Correll 1953). Vanilla flowers are then hand-pollinated and green pods are harvested 9 months later. The green pods are subsequently cured, thereby developing their distinct flavour and black colouration while losing roughly $80 \%$ of their weight (Havkin-Frenkel and Belanger 2018). The resulting black vanilla has strongly increased in price from 2012 to 2019, triggering the expansion of vanilla farming in Madagascar (Hänke and others 2018; Llopis and others 2019; Supplementary Material Figure 1).

In north-eastern Madagascar, vanilla is the main cash crop for smallholder farmers (Hänke and others 2018) who farm the bulk of Madagascar's $40 \%$ share on the world market (FAO 2020). Here, vanilla is almost exclusively produced in rather extensively managed agroforestry systems without the application of fertilizers, herbicides and pesticides. This is partly in contrast to other production areas, such as La Réunion or Mexico, where artificial shade houses are common (Havkin-Frenkel and Belanger 2018). These extensively managed vanilla agroforests also have value for biodiversity: various endemic lemur species live in diverse agroforests (Hending and others 2018) and vanilla agroforests have a more diverse avifauna than open-land uses (Martin and others 2020a). Other prominent land uses in the Malagasy vanilla region include remnant forest fragments, irrigated rice paddies and hill rice fields with the associated herbaceous and woody fallows, that form part of the shifting cultivation cycle, locally known as tavy (Martin and others 2020a; Styger and others 2007). 
The first cycle of shifting cultivation, where fire is used to convert forest into hill rice fields, is the main reason for forest loss in the region (Schüßler and others 2020; Zaehringer and others 2015). This dynamic is consistent with trends across most of Africa, but contrasts with trends in the remaining tropics (Curtis and others 2018; van Vliet and others 2012).

Vanilla agroforests may be established inside forest fragments or on open fallow land, thereby differing in land-use history (Martin and others $2020 a$, b). Forest-derived vanilla agroforests degrade the forest they are established in but will typically outperform shifting cultivation, that is, the replacement of forest with hill rice cultivation, for ecosystem functions and biodiversity (Martin and others 2020a, b). Open-land-derived agroforests may instead restore land formerly under hill rice cultivation by rehabilitating tree cover and preventing the re-occurring fires which characterize the shifting hill rice cultivation system (Holloway 2004; Styger and others 2007). In northeastern Madagascar, 30\% of vanilla agroforests are forest-derived, whereas $70 \%$ are open-land-derived (Hänke and others 2018), further underlining the rehabilitation opportunity offered by openland-derived agroforestry (Figure 1). The high potential for tree rehabilitation and habitat restoration in Madagascar is also recognized in a recent study by Brancalion and others (2019), who attribute the 4th largest restoration opportunity area (in terms of benefits and feasibility) of lowland tropical rainforest to Madagascar. Simultaneously, the country is characterized by high levels of endemism (Goodman and Benstead 2005) and high deforestation rates (Harper and others 2007; Vieilledent and others 2018) and qualifies as a biodiversity hotspot (Myers and others 2000). This exacerbates the need for both effective biodiversity conservation within the existing protected areas and restoration within the agricultural landscape.

In this study, we (1) examined how land-use history, canopy cover, agroforest age, planting density and precipitation influence vanilla yields, (2) assessed tree rehabilitation dynamics across vanilla agroforests of different age and of contrasting land-use history, and (3) investigated how tree rehabilitation within vanilla agroforests may transform the landscape as a whole. To this end, we assessed vanilla yields, canopy cover and canopy height in 209 vanilla agroforests of contrasting land-use history and of different ages ( $0-88$ years), thus representing an 88-year chronosequence. Subsequently, we used remotely sensed canopy cover data to study canopy cover change from 2000 to 2010 on the landscape scale. Based on previous studies from cocoa and coffee agroforests (Blaser and others 2018; Jezeer and others 2017; Perfecto and others 2005), we expected vanilla yields to decline with increasing canopy cover. We further anticipated canopy cover and canopy height to decline with increasing age of forest-derived agroforests, but expected both variables to increase with age in open-land-derived agroforests, in line with the predictions by Martin and others (2020b). At the landscape scale, we presumed that the ongoing transformation of open fallow land into open-landderived agroforests may positively influence canopy cover around the villages.

\section{METHODS}

\section{Study Region}

The SAVA region $\left(25518 \mathrm{~km}^{2}\right.$ /latitude: $14^{\circ} 16^{\prime} \mathrm{S}$, longitude: $\left.50^{\circ} 10^{\prime} \mathrm{E}\right)$ of north-eastern Madagascar is the historic (Correll 1953) and current (Hänke and others 2018) centre of global vanilla production and a biodiversity hotspot (Myers and others 2000). Mean annual temperature is $23.7^{\circ} \mathrm{C}$, and annual rainfall averages at $2238 \mathrm{~mm}$ [Mean across 209 focal agroforests; data from CHELSA climatologies (Karger and others 2017)]. In the southern part of the SAVA region, where we collected the data (Supplementary Material Figure 2), the natural vegetation is tropical rainforest (Vieilledent and others 2018), but only $35 \%$ forest cover remains across the SAVA region (Ferreira Arruda 2018).

\section{Selection of Vanilla Agroforests}

We first selected 60 villages in a stratified-random way for a previous study (Hänke and others 2018). From those 60 , we selected 10 villages in a nested stratified-random way that controlled for village size. Specifically, we randomly selected two villages per village size category (0-1000 people, 10012000 people, $2001-3000$ people, 3000-4000 people, $>4000$ people). Within each village, we chose 14 households randomly from the 30 households included in Hänke and others (2018); however, 20 households opted out, leaving us with 120 households.

We then visited accessible $(<4 \mathrm{~h}$ walking return) vanilla agroforests; 33 households did not own any accessible vanilla agroforests and 27 had more than one agroforest, resulting in a sample of 123 agroforests owned by 87 households. After collecting data from those agroforests, but before doing any data analysis, we checked the number of forest- and open-land-derived agroforests in the 


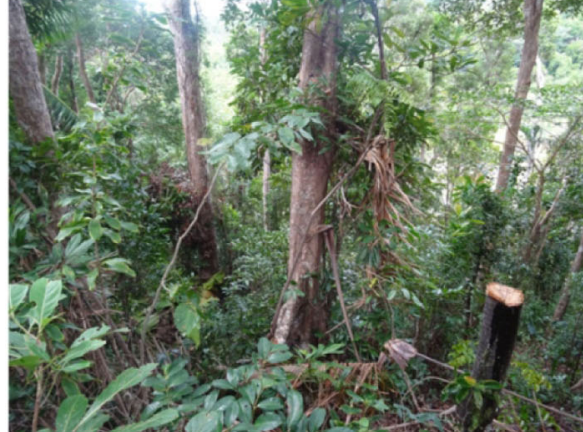

Tropical forest fragment

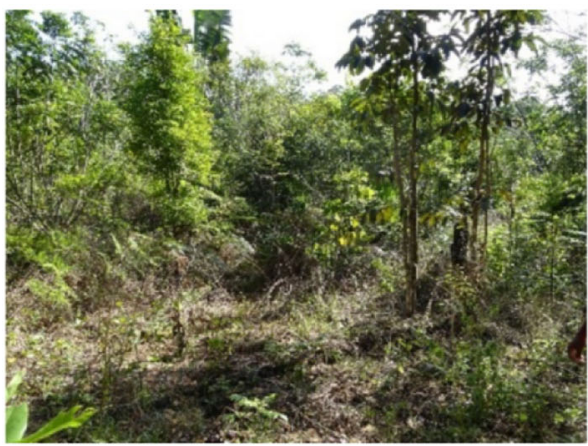

Open land (Woody fallow)

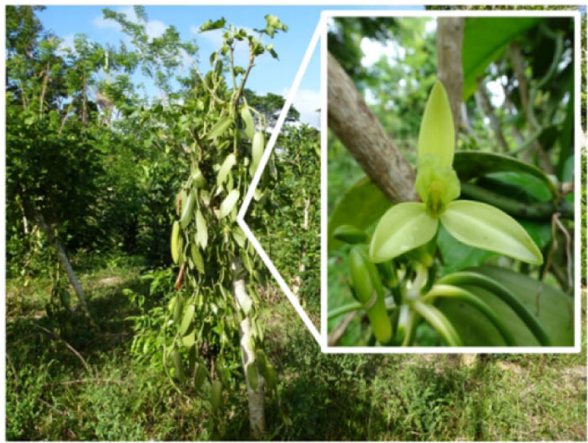

Vanilla pied (unit of vanilla vine and support tree), flower and green pods

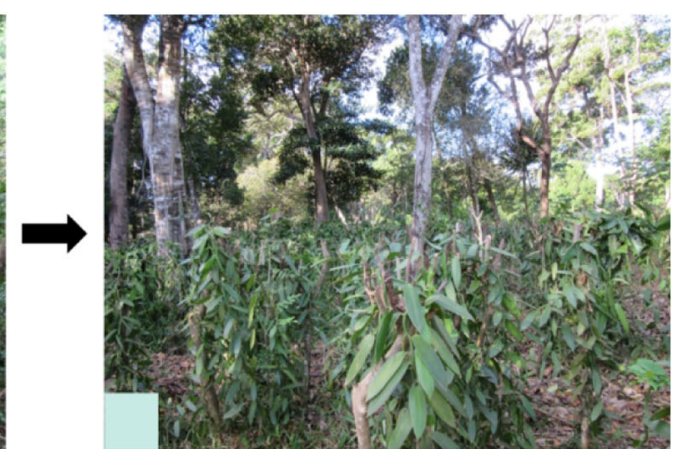

Forest-derived vanilla agroforest

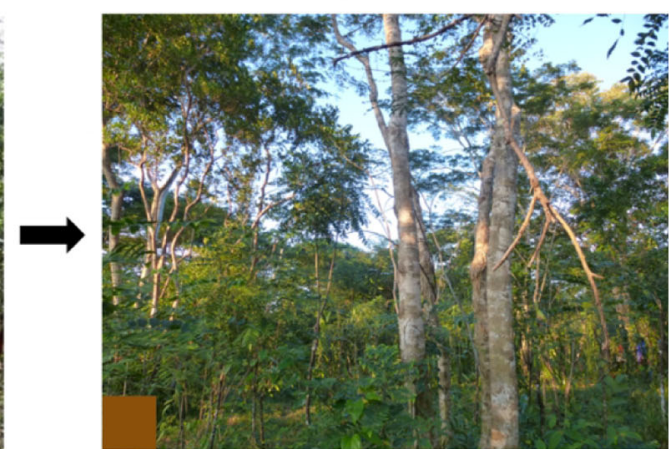

Open-land-derived vanilla agroforest

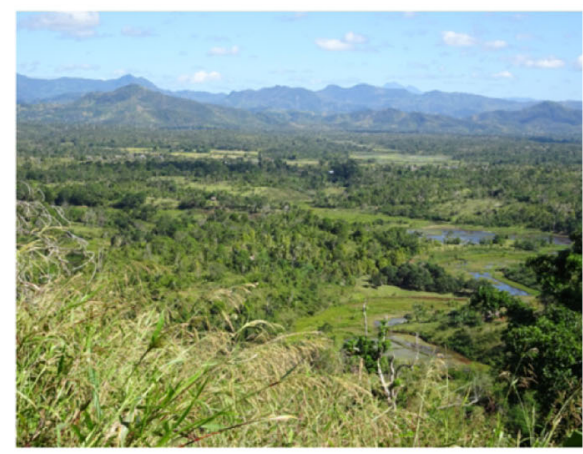

Agricultural landscape in northeastern Madagascar

Figure 1. Top row: Forest-derived vanilla agroforests are directly established inside forest. Middle row: Open-land-derived vanilla agroforests are established on open land, typically woody fallow. Bottom row: Vanilla pied (unit of vanilla vine and support tree) and agricultural landscape in north-eastern Madagascar where the study took place. Colour labels indicate contrasting land-use history of vanilla agroforests and are used throughout the manuscript. All photographs by the authors.

sample and realized that the number was uneven (36 vs. 87).

We thus decided to include four additional villages from the stratified-random sample of 60 villages. For those villages, we knew based on Hänke and others (2018) that their proportion of forestderived vanilla agroforests would be high, resulting in roughly even numbers of forest- and open-landderived agroforests in the final sample. In those four villages, we visited 65 households included in
Hänke and others (2018). Those households owned 86 additional accessible agroforests ( 7 open-landderived, 79 forest-derived). This led to a total sample of 115 forest-derived and 94 open-landderived agroforests (209 in total) owned by 152 households across 14 villages. Supplementary Material Figure 2 shows all 14 villages with field data and the 60 villages from the initial sample. 


\section{Data Collection in Agroforests}

We collected field data between July and October 2018 after the 2018 vanilla harvest.

During visits to the agroforests, we asked vanilla agroforest owners in Malagasy about (1) the realized yield of green vanilla in 2017 and 2018 [ kg agroforest $\left.{ }^{-1}\right]$, (2) estimated green vanilla theft from the agroforest before harvest in 2017 and 2018 [kg agroforest ${ }^{-1}$ ], (3) the number of pieds (combination of vanilla vine and support tree; Figure 1) in the agroforest, (4) the year in which the agroforest was established, and (5) whether the agroforest was forest- or open-land-derived (sensu Martin and others 2020b). Vanilla yields are commonly reported as the weight of green rather than black pods, since green pod weight is independent of the curing technique (Havkin-Frenkel and Belanger 2018). We subsequently added estimated theft to the realized yields as we were interested in the productivity of the agroforests rather than the farmers' income. We measured agroforest size during perimeter walks using handheld GPS devices and applied a slope correction (based on the digital surface model 'ALOS World 3D' (Japan Aerospace Exploration Agency 2018)) to account for different steepness of the terrain. By combining yield data and the slope-corrected agroforest size, we calculated mean green vanilla yield per hectare $\left[\mathrm{kg} \mathrm{ha}^{-1}\right.$ year $\left.^{-1}\right]$ across the two years for further analysis. Based on slope-corrected agroforest size and number of pieds, we calculated planting density [pieds $\mathrm{ha}^{-1}$ ].

We used tablets to assess canopy cover, as photographs from mobile devices have been found to be an adequate, cheap and fast technique to assess canopy cover (Bianchi and others 2017; Tichý 2016). Observers held the tablet (Lenovo YT3850F) above their head (circa $190 \mathrm{~cm}$ ) and used the built-in camera (Lenovo 5C28C02840) with the standard lens and auto-exposure to take a photograph in the azimuthal direction. We repeated this procedure at nine locations per plot (see Supplementary Materials), resulting in 1881 photographs from 209 agroforests. We then classified all photographs into vegetation/sky using the RPackage caiman (Diaz and Lencinas 2015; more details on canopy cover classification in Supplementary Materials) and calculated mean canopy cover across all 9 photographs to derive one value per agroforest. Additionally, the observer estimated the highest point of vegetation above each camera position, enabling us to calculate the mean canopy height across 9 locations for each agroforest.
Some farmers did not know the number of pieds and/or the year of establishment of their agroforest, leading to missing data for planting density and agroforest age in 8 and 3 cases, respectively (out of 209). We imputed these data for the linear mixedeffect models using the mean of each respective variable.

\section{Data Extraction from Raster Layers}

To investigate how precipitation and temperature influenced vanilla yields, we extracted annual mean temperature and annual precipitation for each agroforest from the CHELSA climatologies with a resolution of 30 arc sec (Karger and others 2017) using the plot centre as a reference point. Due to the strong correlation of annual mean temperature and annual precipitation $(-0.76$, Pearson correlation coefficient), we only used elevation and annual precipitation for the analysis on vanilla yields. Analogously, we obtained the elevation of each agroforest from the digital surface model 'ALOS World 3D' (Japan Aerospace Exploration Agency 2018). Lastly, we extracted the percentage landscape forest cover in a radius of $250 \mathrm{~m}$ around plot centres using published binary forest cover data for the year 2017 (Vieilledent and others 2018).

\section{Analysis of Vanilla Yields, Canopy Cover and Canopy Height}

We used three linear mixed-effect models to analyse variation in vanilla yields, canopy cover and canopy height, with 'household' (owner of agroforest, $N=152)$ and 'village' $(N=14)$ as random effects in all models. We fitted all models using the R-Package lme4 version 1.1.21 (Bates 2014) and scaled all explanatory and response variables to zero mean and unit variance, allowing for direct comparison of effect sizes within and across models (Harrison and others 2018). We used an alpha level of 0.05 and calculated marginal and conditional $R^{2}$ values for all models (Nakagawa and Schielzeth 2013). We used QQ-plots to assess normality of model residuals and tested for variable inflation; none of the models had significant deviations in the QQ-plots or variable inflation values above 1.5.

In a first model, we assessed the variation in the response variable green vanilla yield $\left[\mathrm{kg} \mathrm{ha}^{-1}\right]$ in relation to the explanatory variables land-use history (forest- vs. open-land-derived; coded as 1 vs. $0)$, canopy cover, age of agroforest, planting density and annual precipitation. To reach normality of model residuals, we applied a Box-Cox transfor- 
mation to the response variable (Box and Cox 1964). We determined a lambda of 0.25 to be suitable for the transformation using the boxcox function of the R-package mass version 7.3.51.4 (Ripley and others 2013). Due to the highly rightskewed nature of the age and planting density data, we square-root-transformed these two variables. We additionally included interactions between land-use history and all explanatory variables to test whether responses would differ between forest- and open-land-derived agroforests.

In a second and third model, we assessed factors influencing the response variables canopy cover (untransformed) and canopy height (Box-Coxtransformed with lambda 0.35), respectively. We used land-use history, age of agroforest, elevation, landscape forest cover and planting density as explanatory variables. Again, we square-roottransformed the age and planting density data and included interactions between land-use history and all explanatory variables.

In the yield and canopy cover model, none of the interactions were significant, prompting us to present the reduced model without interactions. In the canopy height model, only the interaction between age and land-use history was significant at the $p<0.05$ level. We thus only kept this interaction in the reduced model. All models are presented in full and reduced (that is, final) form in Supplementary Materials (SM Tables 1-3).

To visualize the models, we calculated estimated marginal means and their 95\% confidence intervals using the R-Package emmeans version 1.4.5 (Length and others 2018). We further back-transformed the estimated marginal means to the original distributions to facilitate the interpretation of model results.

\section{Analysis of Canopy cover Dynamics in the Agricultural Landscape}

We used remotely sensed canopy cover data to explore how observed tree rehabilitation within agroforests translated to the landscape scale. We obtained canopy cover data for the years 2000 and 2010 from a Landsat-derived product of continuous canopy cover values with $30 \mathrm{~m}$ resolution (Hansen and others 2013). Using the raster R-package version 3.0.12 (Hijmans and others 2019), we subtracted the 2000 layer from the 2010 layer to obtain a new raster layer with tree cover gains and losses, respectively (change of canopy cover between 2000 and 2010 [\%]). We restricted both layers to an area of $2 \mathrm{~km}$ around the centres of 60 focal villages (excluding any offshore areas), for which we knew that vanilla farming was common and from which we selected the villages for the plot-based part of this study (Village selection described in Hänke and others 2018). We chose $2 \mathrm{~km}$ because agroforests in this range will typically belong to the focal village (personal observation). We then fitted a generalized additive mixed model (GAMM) using the Rpackage $m g c v$ version 1.8-28 (Wood 2012) to evaluate how the dependent variable initial canopy cover in the year 2000' determined the independent variable 'change in canopy cover from 2000 to 2010'. We included 'village' as a random effect and also included longitude and latitude of each raster cell as random effects to control for spatial autocorrelation. Therefore, the model read: change in canopy cover $\sim$ initial canopy cover $+(1)$ village $)+(1$ | longitude $)+(1$ | latitude $)$. We further ran the model on the basic dimension $\mathrm{k}=8$. We checked model assumptions using the gam.check function of the mcgv R-package which demonstrated $\mathrm{k}=8$ to be adequate and a near-normal distribution of residuals.

We analysed all data in $\mathrm{R}$ version 3.6.0 ( $\mathrm{R}$ Core Team 2019). The underlying data and R-code are publicly available (see data availability statement).

\section{RESUlts}

\section{Determinants of Vanilla Yields}

Green vanilla yield per pied varied strongly and ranged from 0 to $860 \mathrm{~g} \mathrm{pied}^{-1}$ year $^{-1}$ with an average of $69.9 \mathrm{~g} \mathrm{pied}^{-1}$ year $^{-1} \quad(\mathrm{SD}=112.3$; $N=209$ agroforests; mean from 2017 and 2018). Note that this estimate includes pieds without any yield as it is calculated by dividing the total yield by the number of pieds in each agroforest. Similarly, green vanilla yields differed strongly across agroforests, ranging from 0 to $932.7 \mathrm{~kg} \mathrm{ha}^{-1} \mathrm{year}^{-1}$ with an average of $154.6 \mathrm{~kg} \mathrm{ha}^{-1}$ year $^{-1}$ (SD = 186.9; $N=209$ agroforests; mean of 2017 and 2018). Using farmgate vanilla prices for the year 2017 (Hänke and others 2018), this average yield translates into mean gross earnings of $4684 € \mathrm{ha}^{-1}$. However, a household in this dataset only farmed 0.46 ha $(\mathrm{SD}=0.42 ; N=152)$ of accessible vanilla agroforests in average. The difference in green vanilla yield per ha between the two years was small (2017: $\quad 158.8 \mathrm{~kg} \mathrm{ha}^{-1} \quad(\mathrm{SD}=200.1) ; \quad 2018$ : $\left.150.2 \mathrm{~kg} \mathrm{ha}^{-1}(\mathrm{SD}=202.6)\right)$, and a Wilcoxon rank-sum test revealed no significant differences between years ( $W=21,267, p=0.642, N=209$ agroforests). Farmers reported green vanilla theft in 26 agroforests (12.4\%) for 2017 and in 25 agroforests $(12.0 \%)$ for 2018 . Farmers who reported 
theft stated that they lost on average $9.15 \mathrm{~kg}$ $(\mathrm{SD}=15.3)$ green vanilla per agroforest in 2017 and $8.72 \mathrm{~kg}(\mathrm{SD}=8.7)$ per agroforest in 2018 .

Our yield model (Figure 2, SM Table 1) revealed that vanilla yields varied independently of land-use history, that is, whether an agroforest was forest- or open-land-derived. Yields were furthermore not significantly related to canopy cover and annual precipitation. Yields rose with increasing agroforest age and planting density. Overall, the marginal $R^{2}$ value of the model was 0.216 , whereas the conditional $R^{2}$-value was 0.450 . The difference between the two values was mainly driven by the random intercept variance for the random effect household' $\left(\tau_{00}=0.26\right)$; the random intercept variance for the random effect 'village' was negligible $\left(\tau_{00}=0.03\right)$.
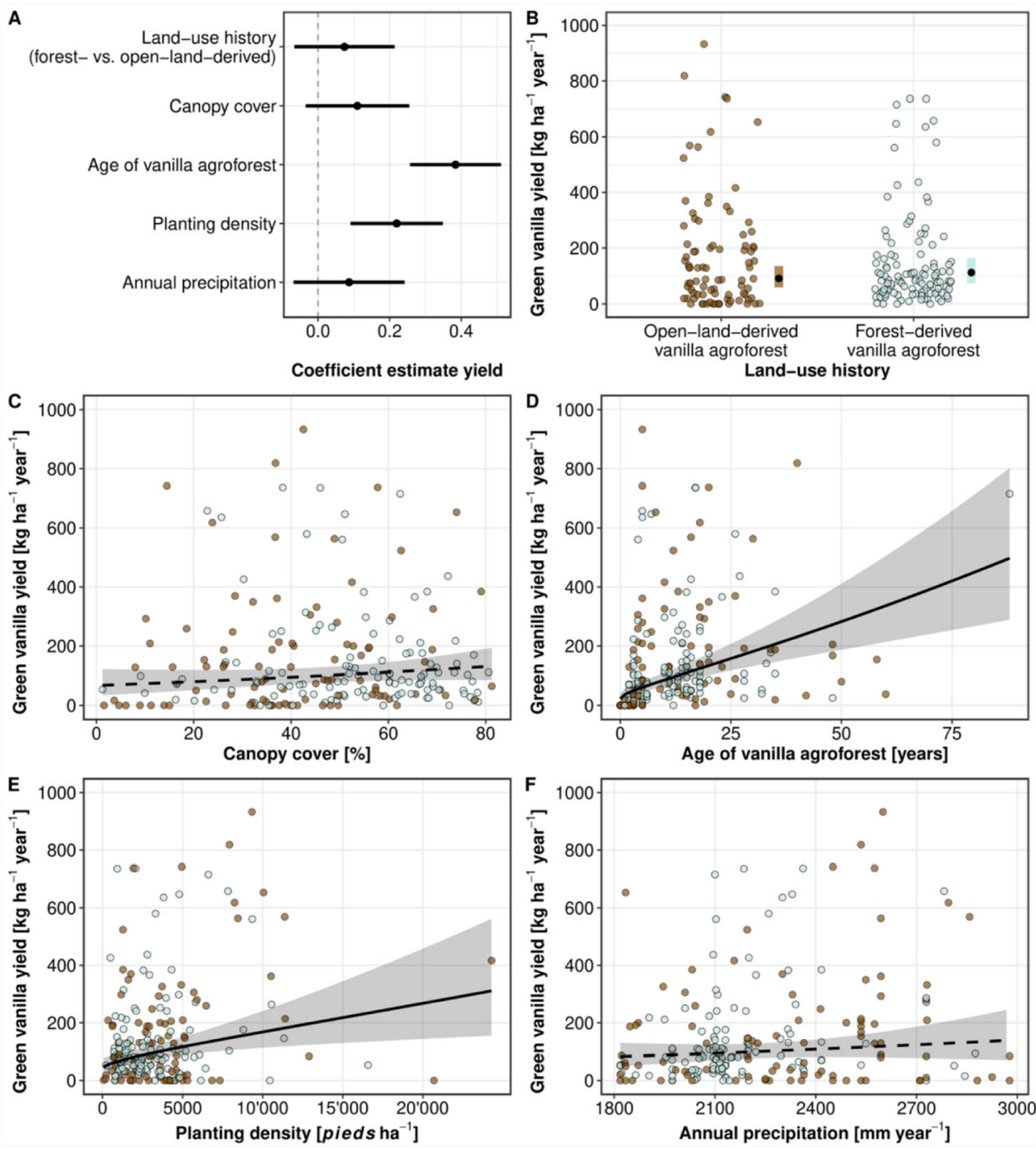

Figure 2. Results of a linear mixed-effect model explaining green vanilla yield [kg ha-1 year $^{-1}$ ] across 209 agroforests. $\mathbf{A}$ Scaled effect plot of the reduced yield model for all five predictors. B-F Green vanilla yields as a function of land-use history $(\mathbf{B})$, canopy cover [\%] $(\mathbf{C})$, age of vanilla agroforest [years] (D), planting density [pieds ha ${ }^{-1}$ ] $(\mathbf{E})$ and annual precipitation [mm year $\left.{ }^{-1}\right](\mathbf{F})$. Green vanilla yields were independent of land-use history and positively associated with all four continuous variables, but the relationships between canopy cover and yields as well as annual precipitation and yields were not significant. Lines and black dots, respectively, show back-transformed estimated marginal means based on the linear mixed-effect model and shaded areas depict 95\% confidence intervals. Points are raw data separated in forestderived (blue) and open-land-derived (brown) agroforests. A table with model results can be found in the Supplementary Materials (SM Table 1). 


\section{Determinants of Canopy Cover and Canopy Height}

Canopy cover was $12.8 \%$ (estimated marginal means $6.3 \%$ ) higher in forest-derived vanilla agroforests $($ mean $=52.9 \%, \mathrm{SD}=17.2)$ compared to open-land-derived agroforests (mean $=40.1 \%$, $\mathrm{SD}=19.0$; Figure 3, SM Table 2). The age of the agroforests differed along the chronosequence between 1 and 88 years in forest-derived agroforests and between 0 and 60 years in open-land-derived agroforests. Age positively related to canopy cover, in both forest- and open-land derived agroforestry: canopy cover increased by $39.5 \%$ (CI $34.5-44.6 \%$ ) over 88 years.

Similarly, canopy height was $8.2 \mathrm{~m}$ (estimated marginal means $5.2 \mathrm{~m}$ ) higher in forest-derived agroforests $($ mean $=14.5 \mathrm{~m}, \mathrm{SD}=7.3$ ) compared to open-land-derived agroforests (mean $=6.3 \mathrm{~m}$, $\mathrm{SD}=4.6$; Figure 3, SM Table 3). The age of the agroforest positively affected canopy height in open-land-derived agroforests where canopy height increased on average by $8 \mathrm{~m}$ (CI 6.1$10.3 \mathrm{~m}$ ) over 60 years. Canopy height in forestderived agroforests was relatively stable (mean decrease of $1.7 \mathrm{~m}$ (CI $-2.7--0.4$ ) over 60 years

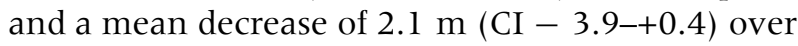
88 years).

Vanilla planting density did not correlate with canopy cover or height (Figure 3, SM Tables 2 and 3). Furthermore, agroforests with more surrounding forest cover had taller trees and greater canopy cover, but confidence intervals overlapped zero for the latter (Figure 3A). Elevation was negatively associated with both tree height and canopy cover (Figure 3A). The canopy cover model (Figure 3,
A
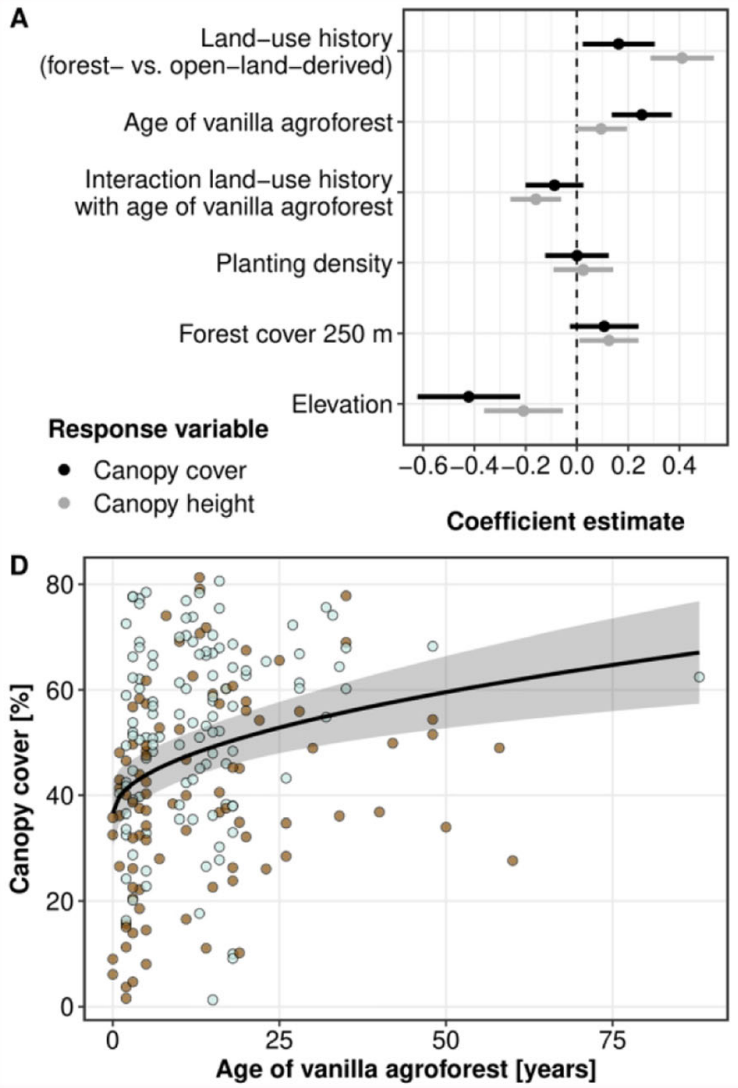
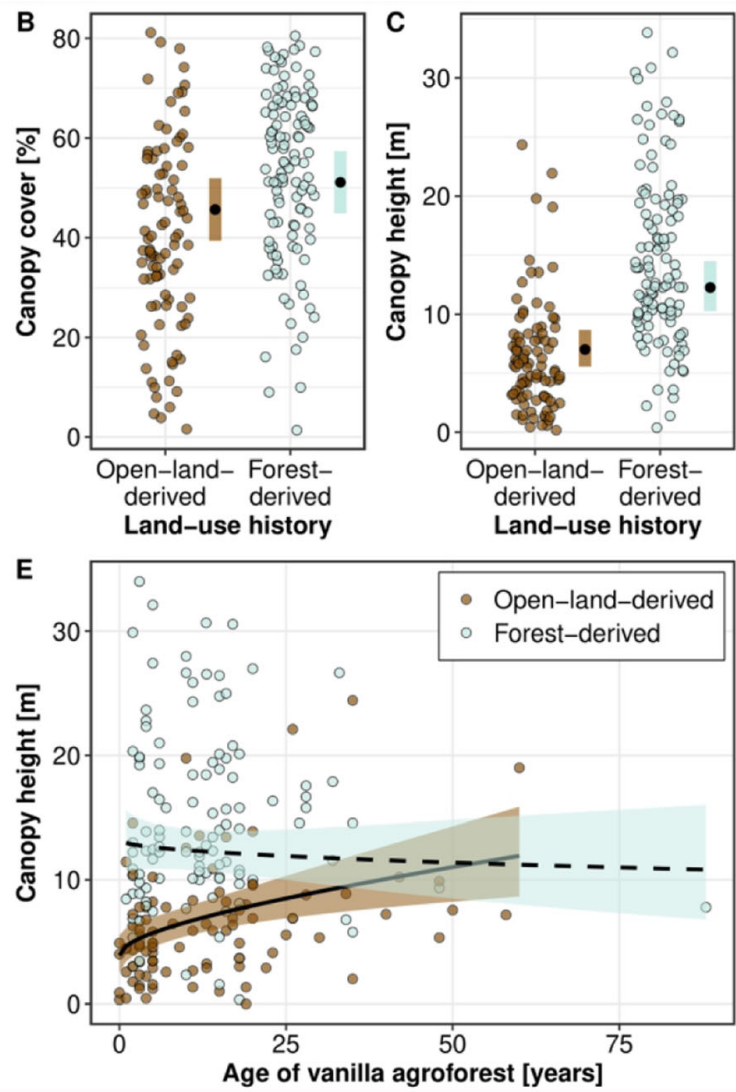

Figure 3. Results of two linear mixed-effect models explaining canopy cover [\%] and canopy height [m] across 209 vanilla agroforests. A Scaled effect plot of the reduced canopy cover model (black) and the reduced canopy height model (grey) for all five predictors, including the interaction between land-use history and age [years] in the canopy height model. B and C Forest-derived agroforests (blue) had both higher canopy height and higher canopy cover compared to open-land-derived agroforests (brown). D Older forest- and open-land-derived agroforests had higher canopy cover. E Older agroforests also had higher canopies, but only if open-land-derived. Lines and black dots, respectively, show backtransformed estimated marginal means based on linear mixed-effect models and shaded areas depict 95\% confidence intervals. Points are raw data separated into forest-derived (blue) and open-land-derived (brown) agroforests. Tables with the results of both models can be found in the Supplementary Materials (SM Tables 2 and 3). 


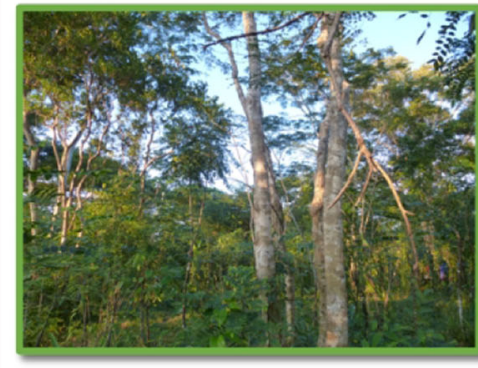

A: Rehabilitation of fallow land, formerly part of the shifting cultivation cycle for hill rice production, through open-landderived vanilla agroforestry is associated with an increase in canopy cover.

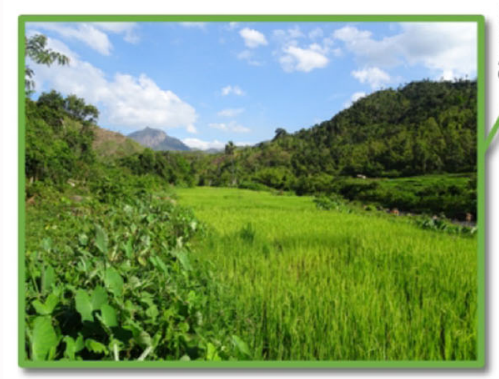

C: No change of land use in productive and valuable rice paddies.
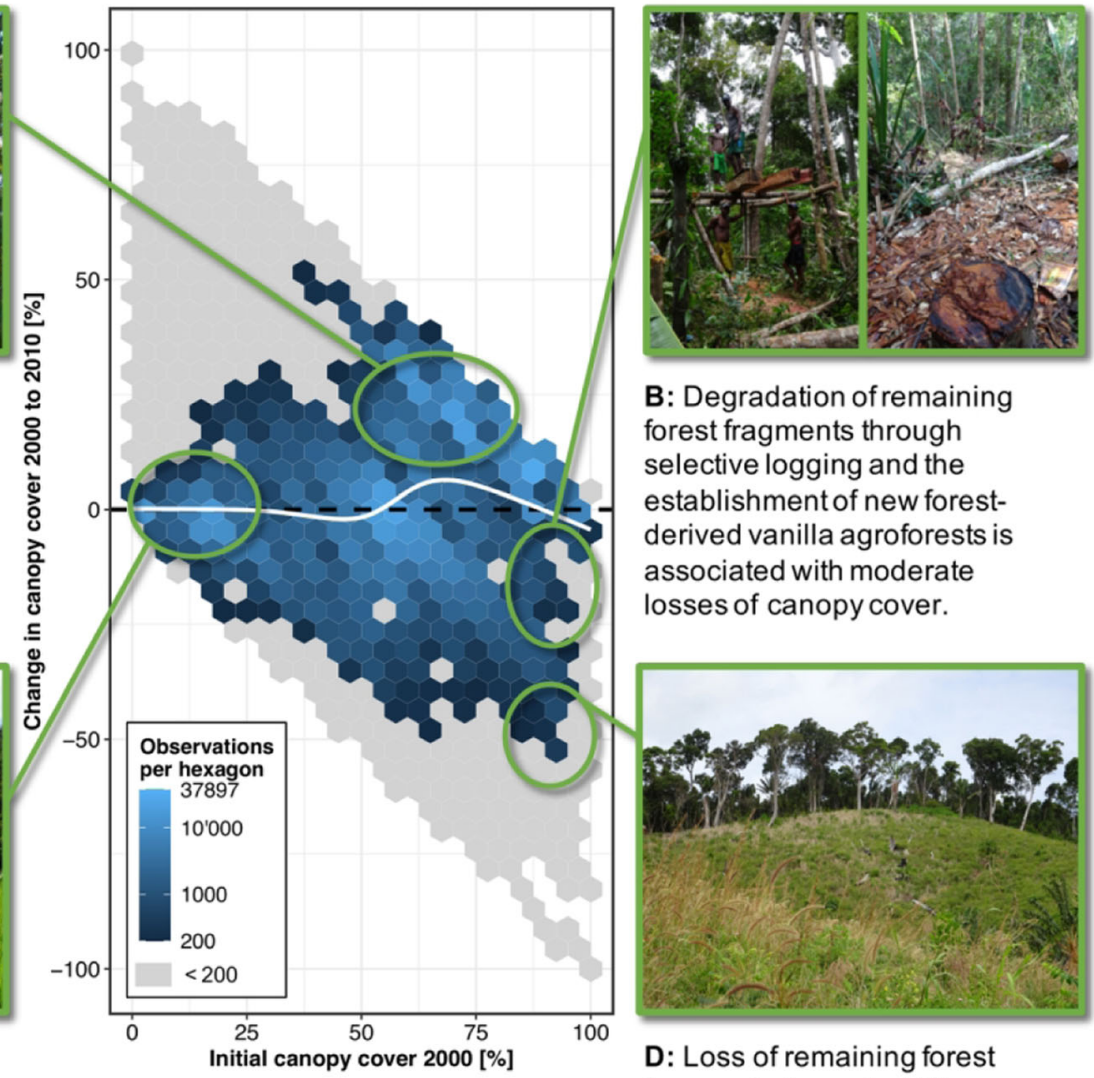

B: Degradation of remaining forest fragments through selective logging and the establishment of new forestderived vanilla agroforests is associated with moderate losses of canopy cover.

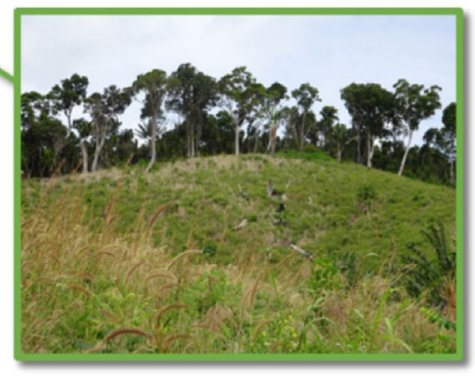

D: Loss of remaining forest fragments through shifting cultivation for hill rice production.

Figure 4. Canopy cover dynamics in the agricultural landscape in a 2-km circle around centres of 60 focal villages between 2000 and 2010 using canopy cover raster data with 30 m resolution (Hansen and others 2013). Canopy cover increased overall by $2.7 \%$, driven by canopy cover increase in areas with medium-to-high initial canopy cover (for example, vanilla agroforests; A). Canopy cover did, however, decrease in areas with very high initial canopy cover (for example, forest; B, D) and was stable in areas with little initial canopy cover (for example, rice paddies; C). The central plot shows hexagon bins of bin-width $5 \%$ which are coloured according to the number of $30 \times 30 \mathrm{~m}$ raster cells (that is, observations) within each hexagon bin. Hexagon bins with less than 200 observations are grey. The white line depicts predicted outcomes of a general additive model explaining change in canopy cover (SM Table 4). All photographs by the authors.

SM Table 2) had a marginal $R^{2}$-value of 0.34 and a conditional $R^{2}$-value of 0.56 , whereas the canopy height (Figure 3, SM Table 3) model had a marginal $R^{2}$-value of 0.35 and a conditional $R^{2}$-value of 0.74 . The substantial difference between conditional and marginal $R^{2}$-values stemmed from the strong explanatory power of the random effect 'household' (canopy cover model: $\tau_{00}=0.16 / \mathrm{ca}-$ nopy height model: $\tau_{00}=0.37$ ); the random intercept variance for the random effect 'village' was small (canopy cover model: $\tau_{00}=0.07 /$ canopy height model: $\tau_{00}=0.02$ ).

\section{Canopy Cover Dynamics in the Agricultural Landscape}

Areas within the agricultural landscape around villages that had low initial canopy cover in the year 2000 experienced little change from 2000 to 2010 (Figure 4C, SM Table 4). Areas with mediumto-high initial canopy cover experienced an increase in canopy cover, reaching the maximum increase of $6.4 \%$ at $68.3 \%$ initial canopy cover (Figure 4A). Areas with very high initial canopy cover lost in average $4.4 \%$ of canopy cover (Figure $4 \mathrm{~B}, \mathrm{D})$. Overall, canopy cover increased by $2.7 \%$. The general additive model explained $8.0 \%$ of the variation in the data. 


\section{Discussion}

Across an 88-year chronosequence of 209 agroforests in the SAVA region of north-eastern Madagascar, we found vanilla yields to vary widely and to be positively affected by planting density and agroforest age, whereas land-use history, canopy cover, and precipitation had no effects on yields. Older vanilla agroforests had higher canopy cover, and, if open-land-derived, also greater canopy height. On the landscape scale, areas within the agricultural landscape with medium canopy cover gained canopy cover between the years 2000 and 2010 .

\section{Determinants of Vanilla Yields}

We found vanilla yields to be hugely variable across agroforests, ranging from 0 to $932.7 \mathrm{~kg}$ green vanilla per hectare. This variability was driven by variable yields per pied (unit of support tree and vanilla vine) and planting densities. Such variability is typical for smallholder agroforests in tropical countries (Clough and others 2011) and points towards large yield gaps caused by sub-optimal management practices (Lobell and others 2009). This also suggests a large intensification potential in existing agroforests and opportunities for sustainable intensification (Tilman and others 2011). Our mean yield estimate of $154.6 \mathrm{~kg} \mathrm{ha}^{-1}$ is lower than most vanilla yield estimates, but published studies cover a large range of rather intensive systems in other growing regions, including plantations with artificial shade (Supplementary Material Table 1), potentially explaining lower yields in rather extensively managed Malagasy agroforests. Our mean yield estimate of $154.6 \mathrm{~kg} \mathrm{ha}^{-1}$ translates into gross earnings of annually $4684 € \mathrm{ha}^{-1}$, exhibiting the exceptional income opportunity vanilla provides under the high prices of the year 2017 (Hänke and others 2018). However, an average rural household in the study region only sells $51.6 \mathrm{~kg}$ of green vanilla per year (Hänke and others 2018; also including households which did not sell any vanilla), and labour demands for the crop are high (Correll 1953). Furthermore, high vanilla prices have led to a surge in local living costs, which are estimated at $5751 €$ per household and year (Hänke and Fairtrade International 2019), and vanilla theft is commonplace (Neimark and others 2019), further impairing the situation for farmers.

In contrast to other studies (Havkin-Frenkel and Belanger 2018; Santosa and others 2005), we do not see yield declines after a certain plantation age
(Figure 2, SM Table 1). The explanation for this is twofold: farmers constantly establish new pieds, resulting in old agroforests that still contain vanilla vines of young and medium age (DAM personal observation). Furthermore, constant 'looping' of vines on the same pied is common: hereby, vanilla vines are guided back down to the soil where new roots establish (Fouché and Jouve 1999). The originally planted part of the vine may die at some point, but the vanilla plant can survive due to the water and soil access that the additional roots provide. Given that new pieds are also propagated by vine cuttings (Fouché and Jouve 1999; HavkinFrenkel and Belanger 2018), planting of new pieds and looping of vines are comparable processes. In combination with the relatively short time to first produce (circa three years; Havkin-Frenkel and Belanger 2018), the looping of vanilla vines may lead to stable yields over time and could thus avoid boom and bust cycles. Such cycles are a common occurrence in other agroforestry crops like cacao (Clough and others 2009) and refer to farmers realizing short-term increases in yields through shade-tree removal at the expense of associated biodiversity and ecosystem functions (Tscharntke and others 2011). The resulting yield increase may be followed by a decrease, caused by elevated pest pressure and dwindling soil fertility (Clough and others 2009). Falling yields prompt the abandoning of plantations and further forest conversion to agroforestry elsewhere (Clough and others 2009). The likely absence of these busts in vanilla agroforests does hence point towards the long-term sustainability of these agroforestry systems.

We also found no link between precipitation and vanilla yields using down-scaled climate data (Figure 2, SM Table 1), suggesting that all villages where these data were collected have generally suitable growing conditions. Nonetheless, the data are not year- or season-specific and can thus only represent general differences in precipitation between sites, possibly hiding effects caused by exceptionally dry or wet years or seasons.

\section{Increasing Vanilla Yields Without Impairing Canopy Cover}

We show that vanilla yields vary independently of canopy cover, suggesting that no trade-offs exist between yields and maintaining or restoring trees (Figure 2, SM Table 1), much in contrast to comparable crops, where yields typically decline above $40 \%$ canopy cover, for example in cacao (Blaser and others 2018; Clough and others 2011) or coffee (Jezeer and others 2017; Perfecto and others 2005). 
The here-shown independence of yields and canopy cover enables farmers to maintain remnant forest trees, which are highly beneficial for ecosystem services and biodiversity (Tscharntke and others 2011), in forest-derived vanilla agroforests, at no direct cost. Furthermore, tree and canopy cover rehabilitation in open-land-derived vanilla agroforests is also possible without compromising on yields. The independence of vanilla yields and shade is supported by plant-physiological experiments which show that vanilla performs well under various light regimes (Díez and others 2017).

Interestingly, vanilla planting density was independent of canopy cover and canopy height (Figure 3, SM Tables 2, 3). This suggests that closing yield gaps is possible by planting vanilla pieds more densely and that doing so does not per se impair canopy cover or height within the currently existing planting density range. Maintaining or promoting trees will likely have positive effects on biodiversity and ecosystem functions (Leakey 2014; Tscharntke and others 2011). For example, predation rates rise with increasing stem density in vanilla agroforests of north-eastern Madagascar (Schwab and others 2020), indicating that trees promote pest control. In sum, the possibility to plant vanilla more densely without impairing canopy cover further strengthens the case for sustainable intensification opportunities in vanilla agroforestry.

\section{Limitations of Yield Data}

Despite methodological improvements over many previous studies (SM Table 1), this study lacks detail on various potential drivers of vanilla yields. This is highlighted by the strong random intercept variance. The random effect 'household' might reflect differences in management practices between households (Hänke and others 2018), whereas 'village' might represent biotic or abiotic villagelevel effects, such as different soil properties. We also acknowledge that the estimation of the weight of stolen vanilla pods, which we had to factor in for $\sim 12 \%$ of agroforests, brings in additional uncertainty. Lastly, our study cannot draw conclusions beyond the range of the data examined, for example the effects of shade on vanilla yields in highly intensified systems. We thus call for more research on vanilla yield determinants that may generate more applicable management advice for farmers.

\section{Increasing Canopy Cover and Tree Height Over Time}

Tree rehabilitation in agroforestry systems is a global priority (FAO 2017). However, many tropical agroforests of key cash crops like cacao or coffee are forest-derived, thus typically contributing to forest degradation rather than tree rehabilitation (Martin and others 2020b). Open-land derived agroforests, on the other hand, may contribute to tree rehabilitation, but empirical chronosequences that document tree recovery in open-land derived agroforests are rare (but see Nijmeijer and others (2019)). Here we show that canopy cover is higher in older forest- and open-land-derived agroforests than in younger ones (Figure 3, SM Table 2). Furthermore, trees were taller in older open-landderived agroforests, but not in older forest-derived agroforest (Figure 3, SM Table 3). This suggests that open-land-derived agroforests can play a key role in tree rehabilitation, given that these agroforests originate from open fallow land. They could thus contribute to increased carbon storage (Nair and others 2009) and the restoration of other ecosystem services (De Beenhouwer and others 2013) while providing new habitat for tree-dependent taxa (Clough and others 2011). To what extent this will be the case also depends on the tree species that farmers allow to regenerate or plant. Here, native trees will be necessary for many biodiversity benefits while introduced fruit and timber trees could provide benefits to farmers (Tscharntke and others 2011).

In contrast to open-land-derived agroforests, canopy cover in forest-derived agroforests will likely only recover after an initial drop at the time of establishment (Martin and others 2020b), which is not covered here as our chronosequence does not include forest fragments. The stable tree height is in line with this interpretation, as the removal of single trees at the time of establishment may not reduce mean tree height at the plot level. Alternatively, the resulting chronosequence could also stem from a change of practices over time, resulting in recently established forest-derived agroforests with low canopy cover in the chronosequence.

Taken together, our results show that forest-derived vanilla agroforests may have relatively stable canopy cover over time and highlight the potential of open-land-derived agroforests to restore ecosystem functions in cultivated landscapes. The transformation of land under shifting cultivation into cash cropping systems is furthermore in line with regional (Andriatsitohaina and others 
2020) and global trends (van Vliet and others 2012).

\section{Canopy Cover Dynamics in the Agricultural Landscape}

We used remotely sensed canopy cover data to explore how observed plot-scale tree rehabilitation translates to the landscape-scale. Comparing canopy cover changes between 2000 and 2010, we found that areas with the lowest initial canopy cover, probably mostly rice paddies, had stable canopy cover (Figure 4, SM Table 4). This is to be expected, given the high productivity of irrigated rice and its local importance for food security (Hänke and others 2018; Laney and Turner 2015), which make a conversion of rice paddies to other land uses unlikely. Areas with very high canopy cover, that is, forest fragments around villages, lost canopy cover over time. Here, small losses may represent forest degradation through selective logging for timber or through the establishment of new forest-derived vanilla agroforests. Some of these areas also showed large losses, likely reflecting shifting cultivation, where forest is cut and burned for hill rice cultivation (Figure 4).

Areas with medium-to-high initial canopy cover showed increases in canopy cover, most likely representing fallows that were transformed to open-land-derived vanilla agroforests. Here, the cessation of repeated burning for shifting cultivation, that comes with the establishment of permanent agroforestry, may have enabled tree rehabilitation at the landscape scale, as observed inside the plots.

Overall, these dynamics resulted in a net increase in canopy cover on the landscape scale, as observed for agricultural landscapes across Madagascar (Zomer and others 2016). The combination of canopy cover gains and losses may be positive for ecosystem services that can be provided by areas with medium canopy cover, such as the provision of fruit or firewood, and for species that can handle habitats with medium canopy cover. Forestdependent species and ecosystem services that depend on high canopy cover, as found in forests, will suffer. Conservation of remaining forests is thus necessary to conserve the large share of Malagasy biodiversity that cannot persist outside forest (Irwin and others 2010). Furthermore, the forests of north-eastern Madagascar have some of the highest carbon stocks of all Malagasy forests (Vieilledent and others 2016), underlining the importance of forest conservation also in the light of climate change mitigation.
Importantly, these findings are limited to the agricultural landscape around 60 focal villages that are predominantly not at the deforestation frontier. Canopy cover dynamics might be different around villages closer to large connecting forest blocks, where an overall increase in canopy cover seems unlikely, given the ongoing deforestation trend in north-eastern Madagascar (Harper and others 2007; Vieilledent and others 2018). Further research elucidating the differences in canopy cover dynamics between villages close and far away from the forest frontier will hence be highly relevant.

\section{ConClusion}

Our main finding, that yields and canopy cover in vanilla agroforests of north-eastern Madagascar varied independently, suggests the possibility to combine high vanilla yields with a high tree cover. This has potential benefits for ecosystem services and biodiversity in a globally important biodiversity hotspot. Our finding contrasts with other agroforestry crops for which higher canopy cover typically impairs yields. Furthermore, the higher canopy cover in older compared to younger vanilla agroforests suggests opportunities to rehabilitate landscapes by enhancing tree cover in open-landderived agroforests. If coupled with effective protection of remaining forests, yield-neutral tree recovery in agroforestry systems could contribute to a multifunctional and biodiversity-friendly agricultural landscape.

\section{ACKNOWLEDGEMENTS}

We are grateful to the research assistants Marie Berthine Maminirina, Grimo Jaona Sedric and Jacqueline Estenie Soa for their help with data collection. We thank all chef de fokontany and farmers for access to sites and information. We collected data under the research permit $\mathrm{N}^{\circ} 18 / 18 / \mathrm{MEEF} / \mathrm{SG} /$ DGF/DSAP/SCB.Re granted by the Ministry of Environment and Sustainable Development, Antananarivo, Madagascar. We thank Gastón Mauro Díaz (https://github.co/GastonMauroDiaz) who developed the algorithm for the adaptive canopy cover thresholding and wrote the R-Script for this, Hendrik Hänke who collected the data from 60 focal villages, Fanilo Andrianisaina who curated household data, Nathaly Guerrero Ramirez and Patrick Weigelt who helped during data analysis, and two reviewers and the editor who gave detailed and constructive feedback. The authors have no conflict of interest to declare. 


\section{FUNDING}

This study was financially supported by the 'Niedersächsisches Vorab' of 'Volkswagen Foundation' as part of the research project 'Diversity Turn in Land Use Science' (Grant Number 11-76251-9935/13(ZN3119)). Open Access funding enabled and organized by Projekt DEAL.

\section{DATA AVAILABILITY}

Data and R-Code are available within the Open Science Framework (OSF): Martin, D. A., Wurz, A., Osen, K., Grass, I., Hölscher, D., Rabemanantsoa, T., Tscharntke, T., Kreft, H. (2020). Shade-tree rehabilitation in vanilla agroforests is yield neutral and may translate into landscape-scale canopy cover gains. OSF. https://doi.org/10.17605/OSF.IO/ J64M8

\section{OPEN ACCESS}

This article is licensed under a Creative Commons Attribution 4.0 International License, which permits use, sharing, adaptation, distribution and reproduction in any medium or format, as long as you give appropriate credit to the original author(s) and the source, provide a link to the Creative Commons licence, and indicate if changes were made. The images or other third party material in this article are included in the article's Creative Commons licence, unless indicated otherwise in a credit line to the material. If material is not included in the article's Creative Commons licence and your intended use is not permitted by statutory regulation or exceeds the permitted use, you will need to obtain permission directly from the copyright holder. To view a copy of this licence, visit http://creativecommons.org/licenses/by/4.0/.

\section{REFERENCES}

Andriatsitohaina RNN, Celio E, Llopis JC, Rabemananjara ZH, Ramamonjisoa BS, Grêt-Regamey A. 2020. Participatory Bayesian network modeling to understand driving factors of land-use change decisions: insights from two case studies in northeast Madagascar. J Land Use Sci 15(1):1-22. https://doi. org/10.1080/1747423X.2020.1742810.

Bastin J-F, Finegold Y, Garcia C, Mollicone D, Rezende M, Routh D, Zohner CM, Crowther TW. 2019. The global tree restoration potential. Science 365(6448):76-9. https://doi.org/10.11 26/science.aax0848.

Bates DM. 2014. Ime4: Mixed-effects modeling with R (Version 1.121) [R-Package].

Bianchi S, Cahalan C, Hale S, Gibbons JM. 2017. Rapid assessment of forest canopy and light regime using smartphone hemispherical photography. Ecol Evol 7(24):10556-66. http s://doi.org/10.1002/ece3.3567.
Blaser WJ, Oppong J, Hart SP, Landolt J, Yeboah E, Six J. 2018. Climate-smart sustainable agriculture in low-to-intermediate shade agroforests. Nat Sustain 1(5):234-9. https://doi.org/10. 1038/s41893-018-0062-8.

Box GE, Cox DR. 1964. An analysis of transformations. J R Stat Soc Ser B (Methodol) 26(2):211-43. https://doi.org/10.1111/j. 2517-6161.1964.tb00553.x.

Brancalion PHS, Niamir A, Broadbent E, Crouzeilles R, Barros FSM, Zambrano AMA, Baccini A, Aronson J, Goetz S, Reid JL, Strassburg BBN, Wilson S, Chazdon RL. 2019. Global restoration opportunities in tropical rainforest landscapes. Sci Adv 5(7):eaav3223. https://doi.org/10.1126/sciadv.aav3223.

Chazdon RL. 2003. Tropical forest recovery: legacies of human impact and natural disturbances. Perspect Plant Ecol Evol Syst 6(1):51-71. https://doi.org/10.1078/1433-8319-00042.

Chazdon RL, Brancalion PHS, Laestadius L, Bennett-Curry A, Buckingham K, Kumar C, Moll-Rocek J, Vieira ICG, Wilson SJ. 2016. When is a forest a forest? Forest concepts and definitions in the era of forest and landscape restoration. Ambio 45(5):538-50. https://doi.org/10.1007/s13280-016-0772-y.

Clough Y, Barkmann J, Juhrbandt J, Kessler M, Wanger TC, Anshary A, Buchori D, Cicuzza D, Darras K, Putra DD, Erasmi S, Pitopang R, Schmidt C, Schulze $\mathrm{CH}$, Seidel D, SteffanDewenter I, Stenchly K, Vidal S, Weist M, Tscharntke T. 2011. Combining high biodiversity with high yields in tropical agroforests. Proc Natl Acad Sci 108(20):8311-16. https://doi. org/10.1073/pnas.1016799108.

Clough Y, Faust H, Tscharntke T. 2009. Cacao boom and bust: sustainability of agroforests and opportunities for biodiversity conservation. Conserv Lett 2(5):197-205. https://doi.org/10. $1111 /$ j.1755-263X.2009.00072.x.

Coe MT, Marthews TR, Costa MH, Galbraith DR, Greenglass NL, Imbuzeiro HMA, Levine NM, Malhi Y, Moorcroft PR, Muza MN, Powell TL, Saleska SR, Solorzano LA, Wang J. 2013. Deforestation and climate feedbacks threaten the ecological integrity of south-southeastern Amazonia. Philos Trans R Soc B Biol Sci 368(1619):20120155. https://doi.org/10.1098/rstb. 2012.0155

Correll DS. 1953. Vanilla-its botany, history, cultivation and economic import. Econ Bot 7(4):291-358. https://doi.org/10. 1007/BF02930810.

Curtis PG, Slay CM, Harris NL, Tyukavina A, Hansen MC. 2018. Classifying drivers of global forest loss. Science 361(6407):1108-11. https://doi.org/10.1126/science.aau3445.

De Beenhouwer M, Aerts R, Honnay O. 2013. A global metaanalysis of the biodiversity and ecosystem service benefits of coffee and cacao agroforestry. Agric Ecosyst Environ 175:1-7. https://doi.org/10.1016/j.agee.2013.05.003.

De Beenhouwer M, Geeraert L, Mertens J, Van Geel M, Aerts R, Vanderhaegen K, Honnay O. 2016. Biodiversity and carbon storage co-benefits of coffee agroforestry across a gradient of increasing management intensity in the SW Ethiopian highlands. Agric Ecosyst Environ 222:193-9. https://doi.org/10.1 016/j.agee.2016.02.017.

Diaz GM, Lencinas JD. 2015. Enhanced gap fraction extraction from hemispherical photography. IEEE Geosci Remote Sens Lett 12(8):1785-9. https://doi.org/10.1109/LGRS.2015.24259 31.

Díez MC, Moreno F, Gantiva E. 2017. Effects of light intensity on the morphology and CAM photosynthesis of Vanilla planifolia Andrews. Revista Facultad Nacional de Agronomía 70(1):8023-33. https://doi.org/10.15446/rfna.v70n1.61736. 
Eitelberg DA, van Vliet J, Doelman JC, Stehfest E, Verburg PH. 2016. Demand for biodiversity protection and carbon storage as drivers of global land change scenarios. Glob Environ Change 40:101-11. https://doi.org/10.1016/j.gloenvcha.2016. 06.014 .

FAO. 2017. Agroforestry for landscape restoration-Exploring the potential of agroforestry to enhance the sustainability and resilience of degraded landscapes (p. 28). http://www.fao.org/ 3/b-i7374e.pdf.

FAO. 2020. FAOSTAT. Food and Agriculture Organisation of the United Nations. http://www.fao.org/faostat/en/\#home.

Ferreira Arruda, T. 2018. Spatial-temporal patterns of deforestation in Northeast Madagascar [MSc Thesis]. University of Goettingen.

Fouché JG, Jouve L. 1999. Vanilla planifolia: history, botany and culture in Reunion island. Agronomie 19(8):689-703. http s://doi.org/10.1051/agro:19990804.

Goodman SM, Benstead JP. 2005. Updated estimates of biotic diversity and endemism for Madagascar. Oryx . https://doi. org/10.1017/S0030605305000128.

Hänke H, Barkmann J, Blum L, Franke Y, Martin DA, Niens J, Osen K, Uruena V, Witherspoon SA, Wurz A. 2018. Socioeconomic, land use and value chain perspectives on vanilla farming in the SAVA Region (north-eastern Madagascar): The Diversity Turn Baseline Study (DTBS). July 2019 Edition. h ttps://doi.org/10.13140/RG.2.2.22059.80163.

Hänke H, Fairtrade International. 2019. Living Income Reference Price for Vanilla from Uganda and Madagascar. Fairtrade International.

Hansen MC, Potapov PV, Moore R, Hancher M, Turubanova SA, Tyukavina A, Thau D, Stehman SV, Goetz SJ, Loveland TR et al. 2013. High-resolution global maps of 21 st-century forest cover change. Science 342(6160):850-3. https://doi.org/10.1 126/science.1244693.

Harper GJ, Steininger MK, Tucker CJ, Juhn D, Hawkins F. 2007. Fifty years of deforestation and forest fragmentation in Madagascar. Environ Conserv 34(04):325-33. https://doi.org/ 10.1017/S0376892907004262.

Harrison XA, Donaldson L, Correa-Cano ME, Evans J, Fisher DN, Goodwin CED, Robinson BS, Hodgson DJ, Inger R. 2018. A brief introduction to mixed effects modelling and multi-model inference in ecology. PeerJ 6:e4794. https://doi.org/10.7717/ peerj. 4794.

Havkin-Frenkel D, Belanger FC, Eds. 2018. Handbook of vanilla science and technology. 2nd edn. Hoboken: Wiley.

Hending D, Andrianiaina A, Rakotomalala Z, Cotton S. 2018. The use of vanilla plantations by lemurs: encouraging findings for both lemur conservation and sustainable agroforestry in the sava region, Northeast Madagascar. Int $\mathrm{J}$ Primatol 39(1):141-53. https://doi.org/10.1007/s10764-018-0022-1.

Hijmans RJ, van Etten J, Cheng J, Mattiuzzi M, Sumner M, Greenberg JA, Lamigueiro OP, Bevan A, Racine EB, Shortridge A 2019. Package 'raster' (Version 3.0-7) [R-Package].

Holl KD, Brancalion PHS. 2020. Tree planting is not a simple solution. Science 368(6491):580-1. https://doi.org/10.1126/sc ience.aba8232.

Holloway L. 2004. Ecosystem restoration and rehabilitation in Madagascar. Ecol Restor 22(2):113-19. https://doi.org/10.33 68/er.22.2.113

Irwin MT, Wright PC, Birkinshaw C, Fisher BL, Gardner CJ, Glos J, Goodman SM, Loiselle P, Rabeson P, Raharison J-L, Raherilalao MJ, Rakotondravony D, Raselimanana A, Rat- simbazafy J, Sparks JS, Wilmé L, Ganzhorn JU. 2010. Patterns of species change in anthropogenically disturbed forests of Madagascar. Biol Conserv 143(10):2351-62. https://doi.org/ 10.1016/j.biocon.2010.01.023.

Japan Aerospace Exploration Agency. 2018. ALOS Global Digital Surface Model "ALOS World 3D: 30 m (AW3D30). http://www.e orc.jaxa.jp/ALOS/en/aw3d30/.

Jezeer RE, Verweij PA, Santos MJ, Boot RGA. 2017. Shaded coffee and cocoa: double dividend for biodiversity and smallscale farmers. Ecol Econ 140:136-45. https://doi.org/10.1016/ j.ecolecon.2017.04.019.

Karger DN, Conrad O, Böhner J, Kawohl T, Kreft H, Soria-Auza RW, Zimmermann NE, Linder HP, Kessler M. 2017. Climatologies at high resolution for the earth's land surface areas Sci Data 4(1):1-20. https://doi.org/10.1038/sdata.2017.122.

Laney R, Turner BL. 2015. The persistence of self-provisioning among smallholder farmers in northeast Madagascar. Hum Ecol 43(6):811-26. https://doi.org/10.1007/s10745-015-9791 -8 .

Leakey RRB. 2014. The role of trees in agroecology and sustainable agriculture in the tropics. Ann Rev Phytopathol 52(1):113-33. https://doi.org/10.1146/annurev-phyto-10231 3-045838.

Length R, Singmann H, Love J (2018) Emmeans: Estimated marginal means, aka least-squares means (Version 1.4.5) [R-Package].

Llopis JC, Harimalala PC, Bär R, Heinimann A, Rabemananjara ZH, Zaehringer JG. 2019. Effects of protected area establishment and cash crop price dynamics on land use transitions 1990-2017 in north-eastern Madagascar. J Land Use Sci 14(1):1-29. https://doi.org/10.1080/1747423X.2019.1625979

Lobell DB, Cassman KG, Field CB. 2009. Crop yield gaps: their importance, magnitudes, and causes. Ann Rev Environ Resour 34(1):179-204. https://doi.org/10.1146/annurev.envir on.041008.093740.

Martin DA, Andriafanomezantsoa R, Dröge S, Osen K, Rakotomalala E, Wurz A, Andrianarimisa A, Kreft H. 2020a. Bird diversity and endemism along a land-use gradient in Madagascar: the conservation value of vanilla agroforests. Biotropica . https://doi.org/10.1111/BTP.12859.

Martin DA, Osen K, Grass I, Hölscher D, Tscharntke T, Wurz A, Kreft H. 2020b. Land-use history determines ecosystem services and conservation value in tropical agroforestry. Conserv Lett 13(5):e12740. https://doi.org/10.1111/conl.12740.

McDowell NG, Allen CD, Anderson-Teixeira K, Aukema BH, Bond-Lamberty B, Chini L, Clark JS, Dietze M, Grossiord C, Hanbury-Brown A, Hurtt GC, Jackson RB, Johnson DJ, Kueppers L, Lichstein JW, Ogle K, Poulter B, Pugh TAM, Seidl $\mathrm{R}, \mathrm{Xu}$ C. 2020. Pervasive shifts in forest dynamics in a changing world. Science 368(6494):eaaz9463. https://doi.org/ 10.1126/science.aaz9463.

Myers N, Mittermeier RA, Mittermeier CG, da Fonseca GAB, Kent J. 2000. Biodiversity hotspots for conservation priorities. Nature 403(6772):853-8. https://doi.org/10.1038/35002501.

Nair PKR, Kumar BM, Nair VD. 2009. Agroforestry as a strategy for carbon sequestration. J Plant Nutr Soil Sci 172(1):10-23. h ttps://doi.org/10.1002/jpln.200800030.

Nakagawa S, Schielzeth H. 2013. A general and simple method for obtaining $R^{2}$ from generalized linear mixed-effects models. Methods Ecol Evol 4(2):133-42. https://doi.org/10.1111/j. 2041-210x.2012.00261.x. 
Neimark B, Osterhoudt S, Blum L, Healy T. 2019. Mob justice and 'The civilized commodity'. J Peasant Stud . https://doi. org/10.1080/03066150.2019.1680543.

Nijmeijer A, Lauri P-E, Harmand J-M, Freschet GT, Essobo Nieboukaho J-D, Fogang PK, Enock S, Saj S. 2019. Long-term dynamics of cocoa agroforestry systems established on lands previously occupied by savannah or forests. Agric Ecosyst Environ 275:100-11. https://doi.org/10.1016/j.agee.2019.02. 004.

Perfecto I, Vandermeer J, Mas A, Pinto LS. 2005. Biodiversity, yield, and shade coffee certification. Ecol Econ 54(4):435-46. https://doi.org/10.1016/j.ecolecon.2004.10.009.

R Core Team. 2019. $R$ : A language and environment for statistical computing (Version 3.6.0) [R].

Ripley B, Venables B, Bates DM, Hornik K, Gebhardt A, Firth D, Ripley MB. 2013. Package 'mass' (Version 7.3.51.4) [R-Package].

Santosa E, Sugiyama N, Nakata M, Kawabata S. 2005. Profitability of Vanilla Intercropping in Pine Forests in West Java. Indonesia. Jpn J Trop Agric 49(3):207-14. https://doi. org/10.11248/jsta1957.49.207.

Schüßler D, Mantilla-Contreras J, Stadtmann R, Ratsimbazafy JH, Radespiel U. 2020. Identification of crucial stepping stone habitats for biodiversity conservation in northeastern Madagascar using remote sensing and comparative predictive modeling. Biodivers Conserv 29:2161-84. https://doi.org/10. 1007/s10531-020-01965-z.

Schwab D, Wurz A, Grass I, Rakotomalala AANA, Osen K, Soazafy MR, Martin DA, Tscharntke T. 2020. Decreasing predation rates and shifting predator compositions along a land-use gradient in Madagascar's vanilla landscapes. J Appl Ecol . https://doi.org/10.1111/1365-2664.13766.

Steffan-Dewenter I, Kessler M, Barkmann J, Bos MM, Buchori D, Erasmi S, Faust H, Gerold G, Glenk K, Gradstein SR, Guhardja E, Harteveld M, Hertel D, Hohn P, Kappas M, Kohler S, Leuschner C, Maertens M, Marggraf R, Tscharntke T. 2007. Tradeoffs between income, biodiversity, and ecosystem functioning during tropical rainforest conversion and agroforestry intensification. Proc Natl Acad Sci 104(12):4973-8. https://d oi.org/10.1073/pnas.0608409104.

Styger E, Rakotondramasy HM, Pfeffer MJ, Fernandes ECM, Bates DM. 2007. Influence of slash-and-burn farming practices on fallow succession and land degradation in the rainforest region of Madagascar. Agric Ecosyst Environ 119(34):257-69. https://doi.org/10.1016/j.agee.2006.07.012.

Tichý L. 2016. Field test of canopy cover estimation by hemispherical photographs taken with a smartphone. J Veg Sci 27(2):427-35. https://doi.org/10.1111/jvs.12350.
Tilman D, Balzer C, Hill J, Befort BL. 2011. Global food demand and the sustainable intensification of agriculture. Proc Natl Acad Sci 108(50):20260-4. https://doi.org/10.1073/pnas.111 6437108

Tscharntke T, Clough Y, Bhagwat SA, Buchori D, Faust H, Hertel D, Hölscher D, Juhrbandt J, Kessler M, Perfecto I, Scherber C, Schroth G, Veldkamp E, Wanger TC. 2011. Multifunctional shade-tree management in tropical agroforestry landscapes-A review. J Appl Ecol 48(3):619-29. https://doi.org/ 10.1111/j.1365-2664.2010.01939.x.

Tscharntke T, Milder JC, Rice R, Ghazoul J. 2014. Conserving biodiversity through certification of tropical agroforestry crops at local and landscape scales. Conserv Lett 8(1):14-23. http s://doi.org/10.1111/conl.12110.

van Vliet N, Mertz O, Heinimann A, Langanke T, Pascual U, Schmook B, Adams C, Schmidt-Vogt D, Messerli P, Leisz S, Castella J-C, Jørgensen L, Birch-Thomsen T, Hett C, BechBruun T, Ickowitz A, Vu KC, Yasuyuki K, Fox J, Ziegler AD. 2012. Trends, drivers and impacts of changes in swidden cultivation in tropical forest-agriculture frontiers: a global assessment. Glob Environ Change 22(2):418-29. https://doi. org/10.1016/j.gloenvcha.2011.10.009.

Vieilledent G, Gardi O, Grinand C, Burren C, Andriamanjato M, Camara C, Gardner CJ, Glass L, Rasolohery A, Rakoto Ratsimba H, Gond V, Rakotoarijaona J-R. 2016. Bioclimatic envelope models predict a decrease in tropical forest carbon stocks with climate change in Madagascar. J Ecol 104(3):70315. https://doi.org/10.1111/1365-2745.12548.

Vieilledent G, Grinand C, Rakotomalala FA, Ranaivosoa R, Rakotoarijaona J-R, Allnutt TF, Achard F. 2018. Combining global tree cover loss data with historical national forest cover maps to look at six decades of deforestation and forest fragmentation in Madagascar. Biol Conserv 222:189-97. https://d oi.org/10.1016/j.biocon.2018.04.008.

Wood S 2012. mgcv: Mixed GAM Computation Vehicle with GCVIAIC/ REML smoothness estimation (Version 1.8-28) [R-Package].

Zaehringer J, Eckert S, Messerli P. 2015. Revealing regional deforestation dynamics in north-eastern madagascar-insights from multi-temporal land cover change analysis. Land 4(2):454-74. https://doi.org/10.3390/land4020454.

Zomer RJ, Neufeldt H, Xu J, Ahrends A, Bossio D, Trabucco A, van Noordwijk M, Wang M. 2016. Global tree cover and biomass carbon on agricultural land: the contribution of agroforestry to global and national carbon budgets. Sci Rep . h ttps://doi.org/10.1038/srep29987. 